\title{
INFLUENCE OF WATER AND MINERAL OIL ON THE LEAKS IN SATELLITE MOTOR COMMUTATION UNIT CLEARANCES
}

\author{
Paweł Śliwiński \\ Gdańsk University of Technology, Poland
}

\begin{abstract}
The article describes the flow rates of mineral oil and water flowing, as working media, through the commutation unit of a hydraulic satellite motor. It is demonstrated that geometrical dimensions of commutation unit clearances change as a function of the machine shaft rotation angle. Methods for measuring the rate of this flow and the pressure in the working chamber are presented. The results of pressure measurements in the working chamber during the transition from the filling cycle to the emptying cycle are included. The pressure in the motor's working chamber changes linearly as a function of the shaft rotation angle, which has a significant effect on the leakage in the commutation unit clearances. The paper presents new mathematical formulas in the form: $Q=f\left(\Delta p^{\gamma}\right)$ to calculate the flow rate of water and mineral oil in the commutation unit clearances. The $\gamma$ factor is described as a function of fluid viscosity and clearance length (the motor shaft rotation angle). The coefficients used in these formulas were determined based on the results of laboratory tests of a motor supplied with water and mineral oil.
\end{abstract}

Keywords: flow in clearances,commutation unit,satellite motor,degree of flow laminarity,water,oil

\section{INTRODUCTION}

The hydraulic motor is the executive element in the hydraulic system. Its purpose is to convert hydraulic energy into mechanical energy. The energy carrier in hydraulic systems is liquid, and its type is conditioned by certain requirements imposed on these systems. In most hydraulic systems, mineral oil is commonly used [35]. However, in some industrial sectors, the basic requirements can include non-flammability of the liquid (mining, steel mills, etc.), or its non-toxicity to the environment and human health (food industry). The liquid which is non-flammable and non-toxic, and certainly suitable for energy transfer in hydraulic systems is water [25].

Throughout the world, there is a growing trend towards research and development of components and hydraulic systems supplied with water $[14,25,30]$.

Such studies are also of particular importance in the marine technology, where hydraulic power circuits are frequently used and water is generally available as working liquid [4]. In comparison to mineral oil, water has very low viscosity and low lubricating properties $[14,15]$. These features adversely influence the efficiency of energy conversion in hydraulic systems $[28,29]$. Despite this, attempts are made to develop innovative components and hydraulic systems supplied with water $[6,25,27,30]$.

So far, each hydraulic device is dedicated to a specific type of working liquid. For example, a hydraulic motor dedicated for oil systems should not be used in systems where the working medium is water $[26,28,29]$.

Both the pump and the hydraulic motor are hydraulic system components in which large energy losses are generated, including volumetric, mechanical and pressure losses $[1,16,17,20,21,22,23,35]$. The scale of these losses is affected by both engine design parameters and liquid properties [2, $3,5,7,8,9,10,11,12,13,18,19,20,24,25,30,33,34]$

The main source of volumetric losses in a hydraulic motor are clearance leakages in the working mechanism and in the commutation unit $[21,24,27,35]$. The results of the past research have proved that the type of working liquid has 
influence on all types of losses. In general, the motor supplied with low viscosity liquid generates greater energy losses than the motor supplied with oil $[27,28]$. The influence of water (as a low viscosity liquid) and mineral oil on the flow in flat gaps of the working mechanism was studied in [28]. This article extends the subject to studying the influence of these media on the flow in the motor's commutation unit clearances.

There is no specific information about hydraulic motors which can be alternatively supplied with water and mineral oil. There is only a rich literature on flows in orifices and other simple openings. Furthermore, no comprehensive studies can be found in the literature that compare the influence of the type of liquid on flow characteristics in the commutation unit clearances.

Therefore, from the scientific and cognitive point of view, the research and description of the influence of water and mineral oil on the flow rate in commutation unit clearances of a hydraulic motor is appropriate and justified. Developing a mathematical model to describe the flow in the motor commutation unit which can be supplied either by high or low viscosity liquid is also appropriate and reasonable. Therefore, the influence of the type of working liquid on the losses in the commutation unit of a hydraulic motor is a new issue and represents an important scientific problem.

The present article focuses on the following objectives:

a) detailed analysis of the flow in the commutation unit clearances of the satellite working mechanism;

b) comparing results of experimental tests of the flow in the commutation unit clearances of the motor supplied with mineral oil and water;

c) developing a mathematical model to describe the flow of water and oil in the satellite motor commutation unit and comparing the results of the experimental research with the mathematical model.

\section{OBJECT OF RESEARCH - SATELLITE MOTOR}

The experimental research of the influence of mineral oil and water as working media on the flow rate in the commutation unit clearances was carried out on a prototype hydraulic satellite motor, marked with the symbol SM-0,75/25. The most recent design of this motor, developed by the author, is shown in Fig. 1.

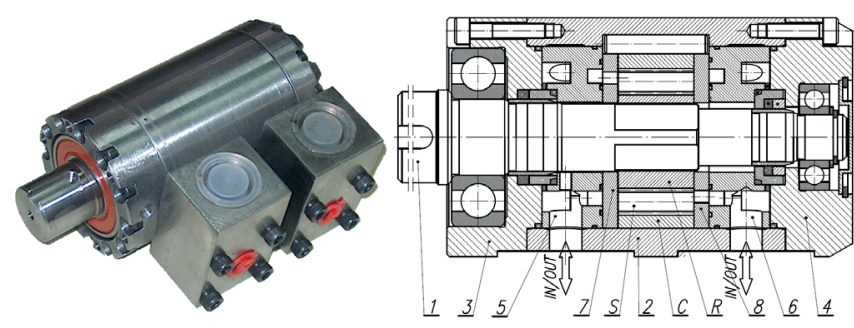

Fig. 1. General view and axial cross section of SM-06 motor: C - curvature, $S$ - satellite, $R$ - rotor, 1 - shaft, 2 - casing, 3 - front casing, 4 - rear casing,

5 and 6 - inlet and exit manifold, 7 and 8 -compensation (commutation) plates $[28,29]$
The toothed unit, shown in Fig. 2, is the satellite working mechanism of the motor. It consists of a toothed rotor $\mathrm{R}$ (4 humps), toothed curvature C (6 humps), and 10 wheels $\mathrm{S}$ (satellite).

The principle of operation of the satellite mechanism is the following: when the rotor rotates, the volume of the space between the satellites changes. This space forms the working chamber. When its volume increases, the filling cycle takes place, while when it decreases, we have the emptying cycle. 24 cycles correspond to one shaft revolution. The chambers in the satellite mechanism are closed by the commutation plates (Fig. 1 - elements 7 and 8, and Fig. 3), which also play the role of compensation plates. Thus, the satellite motor has the ability to compensate axial clearances of the rotor and the satellites. This limits the volumetric losses in the working mechanism [24,26,27,28,29].

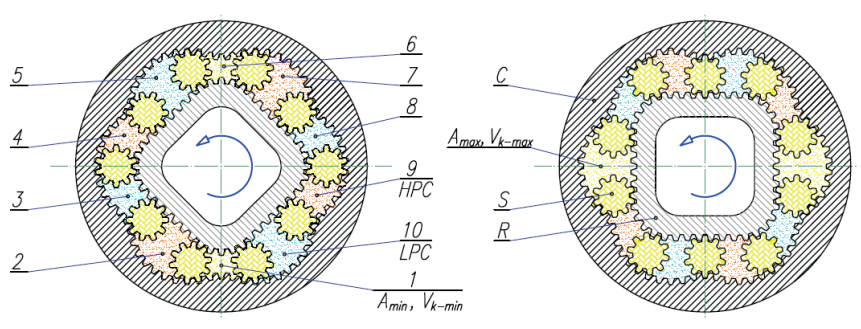

Fig. 2. The working mechanism of the satellite motor: $C$-stator, $R$-rotor, $S$-satellite, $1 \div 10$ - working chambers, LPC - low pressure working chamber, HPC - high pressure working chamber, $V_{k \text {-min }}$ - working chamber with minimum area $A$ (dead chamber), $V_{\text {in }}-$ working chamber with maximum area $A_{\max }[24,26,27,28,29]$.

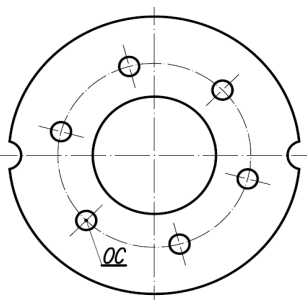

Fig. 3. Distribution plate: OC - inflow/outflow hole [24,26,27,28,29]

The theoretical displacement of the prototype satellite motor used for laboratory tests is $\mathrm{q}_{\mathrm{t}}=32,94 \mathrm{~cm}^{3} / \mathrm{rev}$. The motor was tested using:

- Total Azolla 46 oil $\left(v_{\mathrm{O}}=40 \mathrm{cSt}, \rho_{\mathrm{O}}=873 \mathrm{~kg} / \mathrm{m}^{3}, \mu_{\mathrm{O}}=35\right.$ mPas);

- $\operatorname{water}\left(\nu_{\mathrm{w}}=0,853 \mathrm{cSt}, \rho_{\mathrm{W}}=996 \mathrm{~kg} / \mathrm{m}^{3}\right)$.

\section{COMMUTATION UNIT IN SATELLITE MOTOR}

During the motor shaft rotation, the satellites are moving and properly lock up the inflow holes or open the outflow holes in the compensation plates 7 and 8 (Fig. 1). Correct selection of geometrical dimensions of these holes is very important. The size of the holes has an impact on the volumetric losses. 
The holes in the satellite motor compensation plates have a circular shape (Fig. 3).

Oversized holes (the so-called negative overlap of holes by satellites) cause an unwanted flow of liquid $\mathrm{Q}_{\mathrm{Cm}}$ (so-called flow breakdown) from the high-pressure channel to the lowpressure channel by the death volume (Fig. 4). As a result, the loaded motor generates greater volumetric losses and has, consequently, lower volumetric efficiency. When the stream of liquid supplied to the motor is suitably small, it may even stop the motor. On the other hand, an excessively small diameter of the channels in the compensation plate (the so-called positive overlap of holes by satellites) causes incomplete filling of the working chamber and increases the flow resistance to and from the working chambers. Therefore, a desirable goal is the zero overlap in the satellite motors [27].

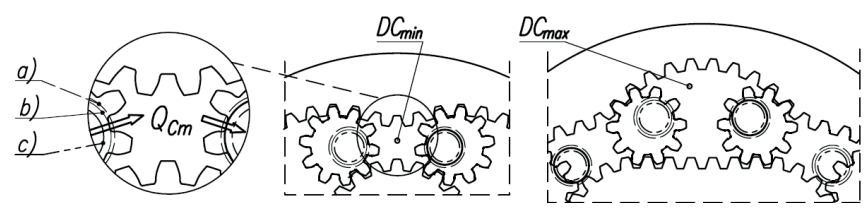

Fig. 4. Overlap of inflow and outflow channels by satellites: a) negative overlap, b) zero overlap, c) positive overlap; $Q_{C m}$ - instantaneous flow in commutation unit clearances and by death volume $D C_{\min }$

In the working satellite mechanism, there is a chamber with the minimum death volume

$\mathrm{DC}_{\min }$ and that with the maximum death volume $\mathrm{DC}_{\max }$ (Fig. 4).

Methodology of flow rate measurement in commutation unit clearances

In order to experimentally determine the value of $\mathrm{Q}_{\mathrm{Cm}}$ in short clearances (at the moment of closing the inflow and outflow channels by satellites) it is necessary to measure the instantaneous flow rate $\mathrm{Q}_{\mathrm{m}}$ at small constant velocity $\mathrm{n}$ and constant pressure drop $\Delta \mathrm{p}$ in the motor. It is possible to keep the rotational speed of the motor low only when it is coupled with the worm gear (Fig. 5). This gear is self-locking and therefore it is required by an electric motor drive.

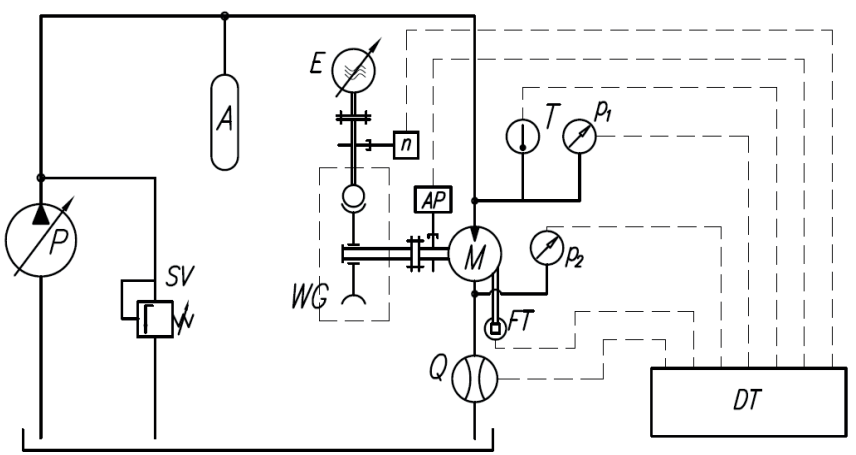

Fig. 5. Scheme of the measuring system: $M$ - tested motor, $P$ - pump, $A$ - accumulator, E-electricmotor with frequency converter, $S V$ - safety valve, $W G$ - worm gear, DT - measurement data recorder, $Q$ - flow meter, $F T$ - force sensor (for moment measurement), $p_{1}$ and $p_{2}$ - pressure sensors, $T$ - temperature sensor, $n_{1}$ - rotational speed sensor, $A P$ - sensor measuring angular position of the shaft
The pressure in the working chambers in the tested motor was measured as well. The pressure sensor location is shown in Fig. 6.
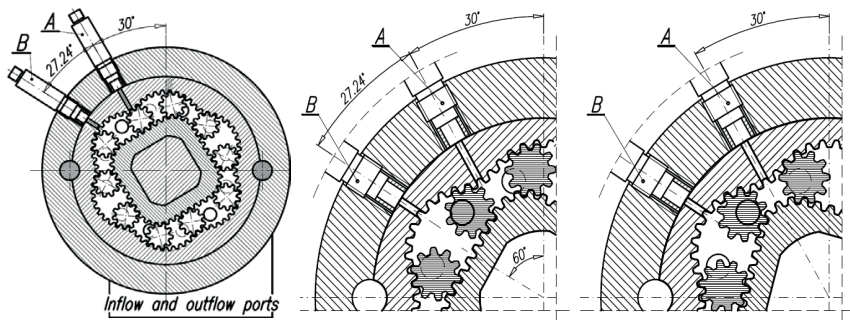

Fig. 6. Method for measuring pressure in motor working chambers: $A$ and $B$ - pressure sensors [27]

\section{RESULTS OF EXPERIMENTAL RESEARCH}

The tests of the motor were conducted at a very low constant speed equal to $1 \mathrm{rpm}$. The results of the flow rate at constant pressure drop were registered for one full rotation of the motor shaft. As a result, the characteristics of the instantaneous flow rate $Q_{m}$ in the motor as a function of the motor shaft rotation angle $\alpha$ were obtained. $Q_{m}$ is a sum:

$$
Q_{m}=\underbrace{q_{t} \cdot n}_{Q_{t}}+\underbrace{Q_{L f g m}+Q_{C m}}_{Q_{L m}}
$$

where:

- $\mathrm{q}_{\mathrm{t}}$ - theoretical motor displacement;

- $\mathrm{n}$ - rotational speed of the motor shaft;

- $\mathrm{Q}_{\mathrm{t}}$ - theoretical flow rate in the motor;

- $\mathrm{Q}_{\mathrm{Lm}}$ - instantaneous volumetric losses;

- $\mathrm{Q}_{\mathrm{Lfgm}}$ - instantaneous flow rate in flat clearances;

- $\mathrm{Q}_{\mathrm{Cm}}$ - instantaneous flow rate in clearances when the inflow and outflow channels are closed by the satellites.

Due to the fact that the engine speed $\mathrm{n}$ is very small, the pressure drop $\Delta \mathrm{p}_{\text {ich }}$ in the internal channels of the motor can be omitted and then the pressure drop $\Delta \mathrm{p}_{\mathrm{i}}$ in the working chambers is equal to:

$$
\Delta \mathrm{p}_{\mathrm{i}}=\Delta \mathrm{p}=\mathrm{p}_{1}-\mathrm{p}_{2}
$$

During one full rotation of the shaft, a 12-peak flow rate $\mathrm{Q}_{\mathrm{Cm}-\mathrm{H}}$ of large values and a 12-peak flow rate $\mathrm{Q}_{\mathrm{Cm}-\mathrm{L}}$ of small values (Fig. 7) (24 peaks in total) are observed. Thus, as many as there are filling and emptying cycles in the working chambers per one shaft rotation. It can be shown that:

- smaller peaks $\mathrm{Q}_{\mathrm{Cm}-\mathrm{L}}$ occur when the death volume $\mathrm{DC}_{\min }$ is formed;

- largest peaks $\mathrm{Q}_{\mathrm{Cm}-\mathrm{H}}$ occur when the death volume $\mathrm{DC}_{\max }$ is formed. 


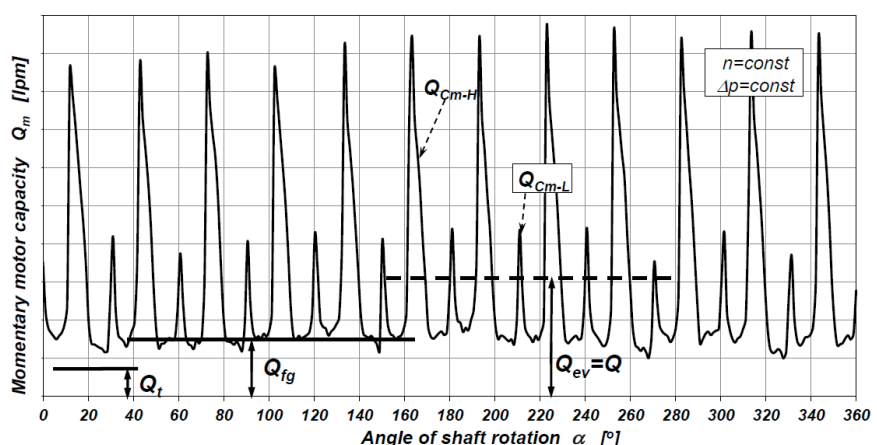

Fig. 7. Characteristic of instantaneous flow rate $Q_{m}$ in the motor $v$ s. shaft rotation angle $\alpha: Q_{C m-H}$-flow rate by maximum death volume, $Q_{C m-L}-$ flow rate by minimum death volume, $Q_{f g}=Q_{t}+Q_{L f g m}$

This is due to:

- satellite movement within the backlash;

- the overlap in the commutation unit. The lowest values of the peaks or no peak at all are observed for positive overlap;

- the accuracy of the shape of rotor and satellite curvatures.

In the satellite mechanism, the death volumes are implemented in pairs. Thus, the peaks of the flow $\mathrm{Q}_{\mathrm{Cm}}$ shown in Fig. 7 refer to a pair of death volumes.

The characteristics of the course of pressure changes in the working chambers are shown in Fig. 8, while Fig. 9 shows pressure change characteristics caused by changing the commutation unit phasing. It is assumed here that $\alpha=0^{\circ}$ corresponds to the position of the operating mechanism for which the maximum death volume or the minimum death volume, optionally, exists. Then, for the zero overlap, the fields $A_{1}$ and $A_{2}$ (Fig. 15) are equal to zero. $Q_{C m}$ forms in a small range of the shaft rotation angle $\alpha$. Fig. 8 and Fig. 9 show that the angle $\alpha$ for which the peak grows or decreases is not greater than $2^{\circ}$.

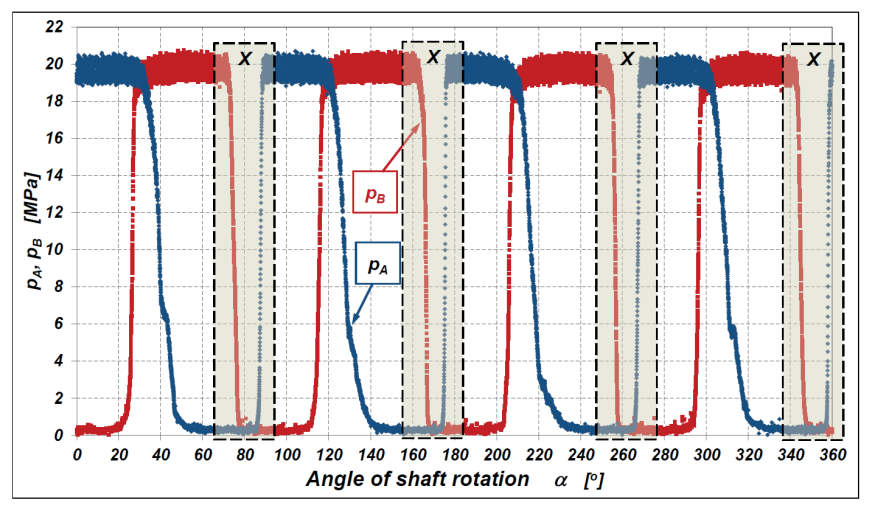

Fig. 8. Characteristics of $p_{A}=f(\alpha)$ and $p_{B}=f(\alpha): p_{A}, p_{B}$-pressure measured by sensor $A$ and $B$, respectively, $X$ - area of sudden pressure drop caused by moving through the dead volume. Inflow and outflow hole diameter $3,8 \mathrm{~mm}$. Supply pressure $20 \mathrm{MPa}$.

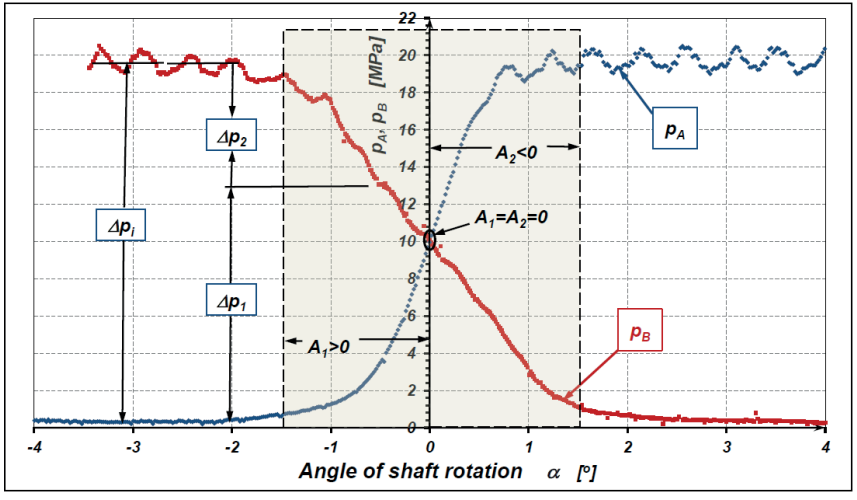

Fig. 9. Area $X$ from Fig. 8. Characteristics of $p_{A}=f(\alpha)$ and $p_{B}=f(\alpha)$.

Changing the commutation unit phase results in a linear pressure change in the chambers (Fig. 9). $\Delta \mathrm{p}_{1}$ and $\Delta \mathrm{p}_{2}$ can be described as:

$$
\begin{aligned}
& \Delta p_{1}=\frac{\Delta p}{2} \cdot\left(1-\frac{\alpha}{1,3}\right) \\
& \Delta p_{2}=\frac{\Delta p}{2} \cdot\left(1+\frac{\alpha}{1,3}\right)
\end{aligned}
$$

Further analysis is carried out for the flow rate $\mathrm{Q}_{\mathrm{Cm}-\mathrm{H}}$ (for the flow rate $\mathrm{Q}_{\mathrm{Cm}-\mathrm{L}}$ the analysis is the same). $\mathrm{Q}_{\mathrm{Cm}}$ is used instead of $\mathrm{Q}_{\mathrm{Cm}-\mathrm{H}}$ for simplification

The experimental characteristics of $\mathrm{Q}_{\mathrm{Cm}}=\mathrm{f}(\alpha>0)$ are shown in Fig. 10. For $\alpha<0$ the shape of the characteristics $\mathrm{Q}_{\mathrm{Cm}}=\mathrm{f}(\alpha<0)$ is a mirror image of the characteristics $Q_{C m}=f(\alpha>0)$. Fig. 11 shows the characteristics $Q_{C m}=f(\Delta p)$, which can be described by the equation:

$$
Q_{C m}=C \cdot \Delta p_{i}^{\gamma}
$$

The values of factors $\mathrm{C}$ and $\gamma$ are shown in Fig. 12 for oil and water, respectively.
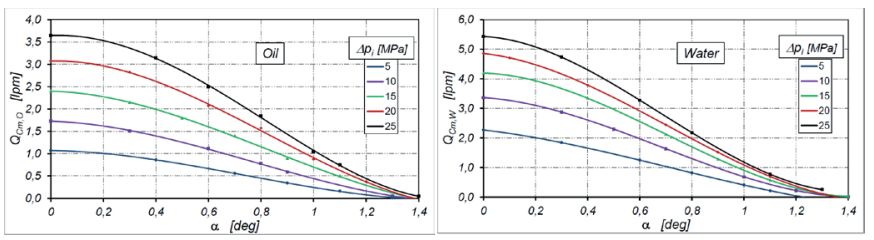

Fig. 10. Characteristics of $Q_{C m}=f(\alpha)$.

Motor supplied with oil (left) and water (right).
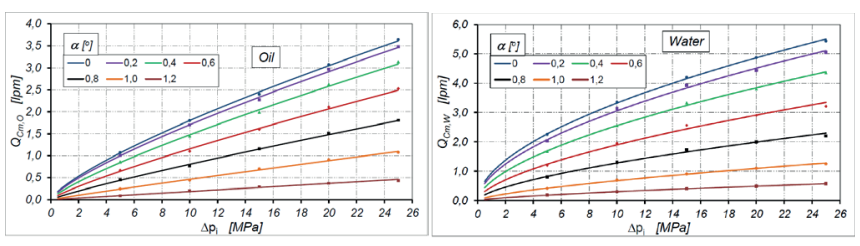

Fig. 11. Characteristics of $Q_{C m}=f(\Delta p)$

Motor supplied with oil (left) and water (right). 


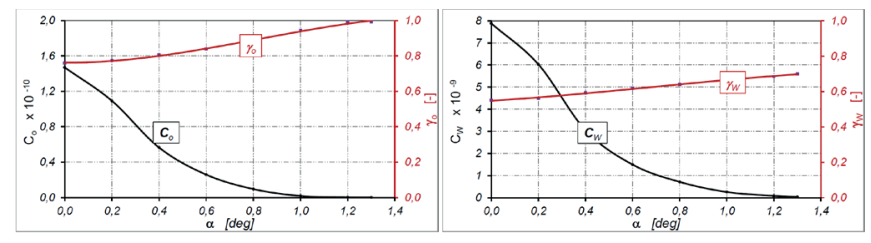

Fig. 12. Characteristics of $C=f(\alpha)$ and $\gamma=f(\alpha)$. Motor supplied with oil (left) and water (right).

The results of the research show (Fig. 13) that the ratio of water flow rate $\mathrm{Q}_{\mathrm{Cm}, \mathrm{W}}$ to oil flow rate $\mathrm{Q}_{\mathrm{Cm}, \mathrm{O}}$ (for $\alpha=$ const.), can be written as the empirical equation:

$$
\frac{Q_{C m, W}}{Q_{C m, O}}=E \cdot \Delta p_{i}^{F}
$$

where $\mathrm{E}$ and $\mathrm{F}$ are factors. The values of $\mathrm{E}$ and $\mathrm{F}$ are shown in Fig. 14 in the form of characteristics. These factors are functions of the shaft rotation angle $\alpha$ (and the clearance length).
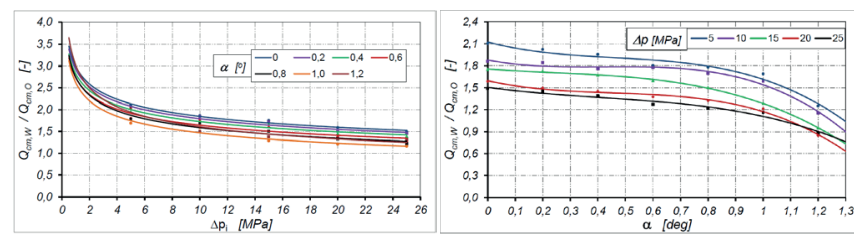

Fig. 13. Characteristics of $Q C m, W / Q C m, O=f(\Delta p)$ (left) and $Q C m, W / Q C m, O=f(\alpha)$ (right).

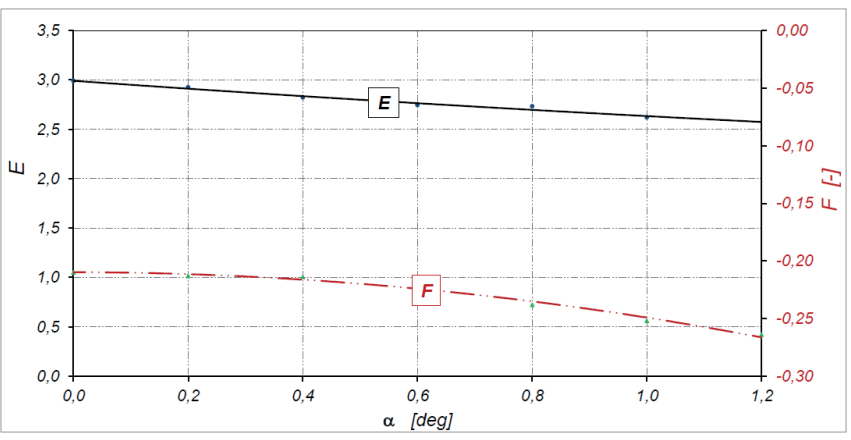

Fig. 14. Characteristics of $E=f(\alpha)$ and $F=f(\alpha)$.

\section{MECHANISM OF $Q_{C M}$ FLOW RATE FORMATION IN COMMUTATION UNIT CLEARANCES}

The mechanism of flow rate $\mathrm{Q}_{\mathrm{Cm}}$ formation in commutation unit clearances is shown in Fig. 15.
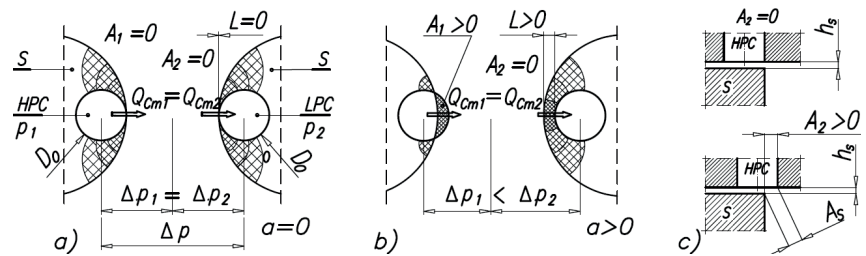

Fig. 15. Position of satellites relative to high pressure hole HPC and lowpressure hole LPC. Zero overlap: a) typical position of satellites for maximum or minimum death volume; b) process of filling the working chamber c) clearance dimensions for the characteristic position of the satellite.
As shown in Fig. 15, the clearances are arranged in series. For such a case:

$$
\begin{gathered}
Q_{C m 1}=Q_{C m 2}=Q_{C m} \\
\Delta p_{1}+\Delta p_{2}=\Delta p_{i}=\Delta p
\end{gathered}
$$

For $\alpha=0$ the flow area $A_{1}$ is proportional to hole diameter $\mathrm{D}_{\mathrm{o}}$ and to clearance height $\mathrm{h}_{\mathrm{s}}$ :

$$
A_{1}=C_{2} \cdot D_{o} \cdot h_{S}
$$

where $\mathrm{C}_{2}$ is the coefficient of proportionality. To simplify further discussion, $\mathrm{C}_{2}=1$ is adopted.

In the tested satellite motor, the angle range is $\alpha=\left(0^{\circ} ; 2^{\circ}>\right.$, and $\mathrm{A}_{2}$ is expressed as:

$$
A_{2}=0,107 \cdot m^{2} \cdot|\alpha|
$$

Therefore, for $\alpha>0$, the flow cross-sectional area $A_{s}$ is:

$$
A_{s}=\sqrt{{A_{1}{ }^{2}+{A_{2}}^{2}}^{2}}=\sqrt{D_{o}{ }^{2} \cdot{h_{s}}^{2}+0,107^{2} \cdot m^{4} \cdot \alpha^{2}}
$$

For $\alpha>0$ the length $\mathrm{L}$ of the clearance is a function of the teeth module $m$ and the shaft rotation angle $\alpha$. In the satellite mechanism, for $\alpha=\left(0^{\circ} ; 2^{\circ}>\right.$, the following relationship is true:

$$
L=0,213 \cdot m \cdot \alpha
$$

\section{KNOWN METHODS DESCRIBING THE FLOW IN SHORT CLEARANCES}

In the literature, the flow in the commutation unit is treated as:

- an average value, independent of the shaft rotation angle $[1,21,22]$;

- a turbulent volumetric loss component, related to the theoretical capacity $\mathrm{q}_{\mathrm{t}}$ of the motor $[1]$ :

$$
Q_{C}=C_{t} \cdot \sqrt{\frac{2}{\rho} \cdot \Delta p} \cdot \sqrt[3]{\left(\frac{q_{t}}{2 \cdot \pi}\right)^{2}}
$$

where:

- $\mathrm{C}_{t}$ - coefficient of proportionality,

$-\rho$ - density of liquid.

The liquid flow in the commutation unit clearances a is a typical case of the flow in:

- a sharp-edged clearance (orifice type);

- a flat clearance with a very small length.

In $[31,32]$ the flow rate in short clearances is described by the following formula: 
$Q=C_{d \infty} \cdot\left(1+a \cdot e^{\frac{-\delta_{1}}{C_{d \infty}} \cdot \sqrt{R e}}+b \cdot e^{\frac{-\delta_{2}}{C_{d \infty}} \cdot \sqrt{R e}}\right) \cdot A \cdot \sqrt{\frac{2}{\rho} \cdot \Delta p}$

where:

- A - cross-sectional area of the clearance,

- a, b, $\delta_{1}, \delta_{2}$, - specific flow dependent coefficients,

- $\mathrm{C}_{d \infty}$ - turbulent discharge coefficient.

For clearance types shown in Fig. 16, A and Re are [31]:

$$
\begin{gathered}
A=w \cdot x \\
R e=2 \cdot \frac{Q \cdot \rho}{w \cdot \mu}
\end{gathered}
$$

respectively,
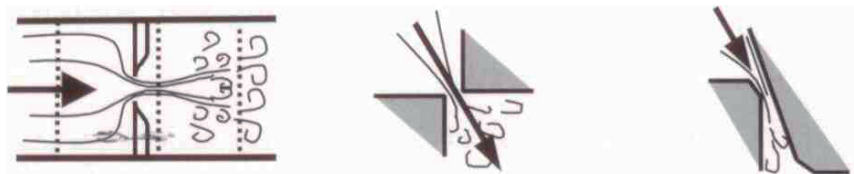

Fig. 16. Different types of holes: orifice and short clearances [32].

while for the type shown in Fig. 17, A is [31]:

$$
A(x)=\frac{w \cdot x}{1-e^{-\frac{x}{d_{0}}}}
$$

In the above equations:

- w - clearance width,

- $\mathrm{x}$ - dimension of the clearance opening,

$-d_{0}-$ clearance height for $\mathrm{x}=0$.
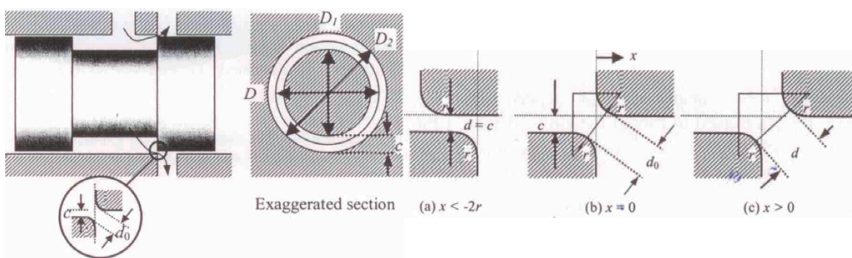

Fig. 17. Flow in rectangular orifice of directional valve spool (left) and enlarged scenario of spool and sleeve chamfers (right) [31].

Equation (14) cannot be used to describe the flow in motor commutation unit clearances because:

- it is an implicit equation;

- there is a laminar flow component at low flow rates of liquid in the clearance. Consequently, describing a partially turbulent flow as function $\Delta \mathrm{p}^{0,5}$ is not appropriate;

- clearances change their dimensions during motor shaft rotation, i.e. the clearance dimensions are a function of the shaft rotation angle $\alpha$.

Therefore, a detailed analysis of the flow in short clearances of the satellite mechanism commutation unit is justified, as it will allow to simulate more accurately the characteristics of volumetric losses in the hydraulic motor.

\section{MATHEMATICAL MODEL OF FLOW RATE IN COMMUTATION UNIT CLEARANCES}

Based on the above experimental results, it has been concluded that the flow in both clearances (Fig. 15) is turbulent and not fully developed.

For $\alpha>0$ the first clearance (Fig. 15) has the cross-sectional area $A_{s}=f(\alpha)$. It is assumed that:

and

$$
Q_{C m 1}=Q_{C m}=\underbrace{A_{S} \cdot\left(\frac{2}{\zeta \cdot \rho}\right)^{0,5}}_{C_{1}} \cdot \Delta p_{1}^{0,5}
$$

$$
\begin{gathered}
\zeta=\frac{K_{1}}{R e^{\beta_{1}}} \\
R e=\frac{c_{1} \cdot A_{s}{ }^{0,5}}{v}
\end{gathered}
$$

The relations between $\mathrm{c}_{1}$ and $\mathrm{A}_{\mathrm{s}}$ is:

$$
c_{1}=\frac{Q_{C m 1}}{A_{s}}
$$

Taking into account Equations (3) and (11), the flow rate is:

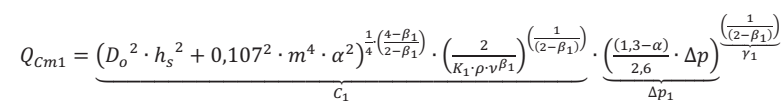

In the second slot, the flow can be described by the formula [5]:

$Q_{C m 2}=Q_{C m}=\left(\frac{1}{v}\right)^{\left(\frac{\beta_{2}}{2-\beta_{2}}\right)} \cdot\left(\frac{1}{K_{2} \cdot \rho}\right)^{\left(\frac{1}{2-\beta_{2}}\right)} \cdot b \cdot\left(\frac{2 \cdot h_{s}{ }^{3}}{L}\right)^{\left(\frac{1}{2-\beta_{2}}\right)} \cdot \Delta p_{2}{ }^{\left(\frac{1}{2-\beta_{2}}\right)}$

Assuming $\mathrm{b}=\mathrm{D}_{0}$ and taking into account the relationship (4) and (12) we get:

$Q_{C m 2}=\underbrace{D_{o} \cdot\left(\frac{9,39 \cdot h_{s}{ }^{3}}{m \cdot \alpha \cdot K_{2} \cdot \rho \cdot \nu_{2}}\right)^{\left(\frac{1}{2-\beta_{2}}\right)}}_{C_{2}} \cdot \underbrace{\left(\frac{(1,3+\alpha)}{2,6} \cdot \Delta p\right)^{\frac{\left(\frac{1}{2-\beta_{2}}\right)}{\gamma_{2}}}}_{\Delta p_{2}}$

There are two unknowns in each of Equations (22) and (24), which are: $K_{1}, \beta_{1}, K_{2}$ and $\beta_{2}$. Nonetheless, for the flow:

- $b_{1}=0$ cannot be accepted in the first clearance;

$-b_{2}=1$ cannot be accepted in the second clearance.

If $\alpha$ increases, then:

a) $\mathrm{A}_{\mathrm{s}}$ increases in the first clearance;

b) $\Delta \mathrm{p}_{1}$ decreases and $\Delta \mathrm{p}_{2}$ increases;

c) length $\mathrm{L}$ of the second clearance increases;

d) the low rate in both clearances decreases.

Therefore, the flow becomes less disturbed in both clearances. Hence, $\gamma$ is growing in both cases. It is proposed to assume that:

$$
\gamma_{1}=\gamma_{2}=\gamma
$$


which leads to:

$$
\beta_{1}=\beta_{2}
$$

Due to the fact that $Q_{C m 1}=Q_{C m 2}=Q_{C m}$, and comparing (22) and (24) to (5) we arrive at:

$$
C_{1} \cdot\left(\frac{1,3-\alpha}{2,6}\right)^{\gamma}=C_{2} \cdot\left(\frac{1,3+\alpha}{2,6}\right)^{\gamma}=C
$$

The above analysis shows that the flow rate $Q_{\mathrm{cm}}$ in satellite motor commutation unit clearances can be described both by formula (22) and formula (24).

Taking into account $\mathrm{C}_{1}$ and $\mathrm{C}_{2}$ from equations (22) and (24), the coefficients $\mathrm{K}_{1}$ and $\mathrm{K}_{2}$ can be calculated as:

$$
\begin{gathered}
K_{1}=\frac{(1,3-\alpha)}{1,3} \cdot \frac{\left(D_{o}{ }^{2} \cdot h_{s}{ }^{2}+0,107^{2} \cdot m^{4} \cdot \alpha^{2}\right)^{\left(0,5+\frac{1}{4 \cdot \gamma}\right)}}{C^{\left(\frac{1}{\gamma}\right)} \cdot \rho \cdot v^{\left(2-\frac{1}{\gamma}\right)}} \\
K_{2}=3,61 \cdot\left(1+\frac{1,3}{\alpha}\right) \cdot\left(\frac{D_{o}}{C}\right)^{\left(\frac{1}{\gamma}\right)} \cdot \frac{h_{s}{ }^{3}}{m \cdot \rho \cdot v^{\left(2-\frac{1}{\gamma}\right)}}
\end{gathered}
$$

These coefficients are functions of the motor shaft rotation angle. Therefore, they depend on the length of the clearances. The values of these coefficients are shown in Fig. 18.
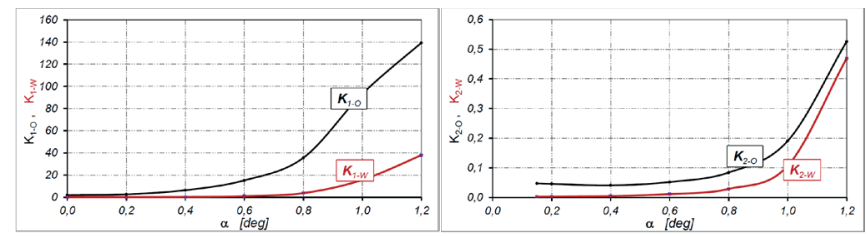

Fig. 18. Characteristics: $K_{1,0}=f(\alpha)$ and $K_{2,0}=f(\alpha)$ for motor supplied with oil; $K_{1, W}=f(\alpha)$ and $K_{2, W}=f(\alpha)$ for motor supplied with water.

\section{AVERAGE VALUE OF PEAK FLOW}

The average value of one peak flow is:

$$
Q_{C m-a v}=\frac{1}{\alpha} \cdot \int_{0}^{\alpha} Q_{C m} d \alpha
$$

The average value of the flow in clearances during one shaft rotation is:

$Q_{C}=\frac{z_{C} \cdot z_{R}}{720} \cdot\left(\int_{0}^{\alpha_{H}} Q_{C m-H} d \alpha+\int_{0}^{\alpha_{L}} Q_{C m-L} d \alpha\right)$

where:

- $\mathrm{Z}_{\mathrm{R}}$ - number of rotor humps,

- $z_{C}-$ number of curvature humps;

- $a_{\mathrm{H}}$ - angle at which a higher flow peak [deg] disappears or is formed;
- $a_{L}-$ angle at which a lower flow peak [deg] disappears or is formed.

The experimental research (Fig. 7) has shown that:

$$
\frac{Q_{C m-H-a v}}{Q_{C m-L-a v}} \approx 2,5
$$

Thus, for $\mathrm{z}_{\mathrm{R}}=4$ and $\mathrm{z}_{\mathrm{C}}=6$

$$
Q_{C}=\frac{33,6}{360} \cdot \int_{0}^{\alpha_{H}} Q_{C m-H} d \alpha
$$

Due to the fact that coefficient $\beta$ depends on the shaft rotation angle, the integral in Equation (35) has no solution. Therefore, it is proposed to simplify the problem and assume that the average value:

a) for a single higher peak is equal to:

$$
Q_{C m-H-a v}=\frac{\left(Q_{C m-H}\right)_{\alpha=0}}{2}
$$

b) for a single lower peak is equal to (according to (34)):

$$
Q_{C m-L-a v}=\frac{\left(Q_{C m-H}\right)_{\alpha=0}}{5}
$$

c) during one rotation of the shaft, for $\mathrm{z}_{\mathrm{R}}=4$ and $\mathrm{z}_{\mathrm{C}}=6$, in analogy to (33):

$$
Q_{C}=0,0932 \cdot \alpha_{\max } \cdot\left(Q_{C m-H-a v}\right)_{\alpha=0}
$$

Here, $\alpha_{\max }$ is the angle for which the peak is equal to zero. In this case $\alpha_{\max }=1,3$. In addition, for $\alpha=0$ the coefficient:

- $\beta_{1, \mathrm{O}}=0,684$ and $\beta_{1, \mathrm{~W}}=0,183$;

- $\mathrm{K}_{1, \mathrm{O}}=1,792$ and $\mathrm{K}_{1, \mathrm{~W}}=0,0144$.

Hence:

- for oil:

$Q_{C, O}=0,077 \cdot\left(D_{o} \cdot h_{S}\right)^{1,26} \cdot\left(\frac{1}{\rho_{O} \cdot v_{O} 0,684}\right)^{0,76} \cdot \Delta p^{0,76}$

- for water:

$Q_{C, W}=1,25 \cdot\left(D_{o} \cdot h_{S}\right)^{1,05} \cdot\left(\frac{1}{\rho_{W} \cdot v_{W} 0,183}\right)^{0,55} \cdot \Delta p^{0,55}$

The characteristics of $\mathrm{Q}_{\mathrm{C}, \mathrm{O}}$ and $\mathrm{Q}_{\mathrm{C}, \mathrm{W}}$ obtained based on experimental data and calculated from formulas (39) and (40) are compared in Fig. 19.
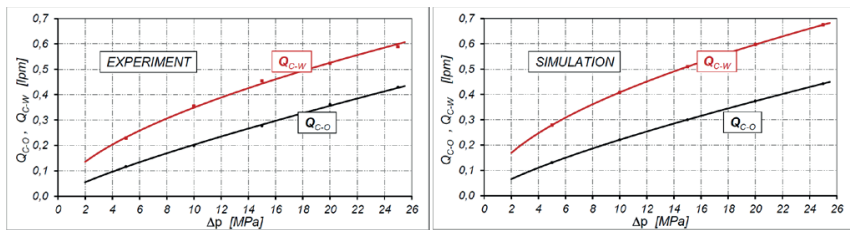

Fig. 19. Characteristics of $Q_{C W}=f(\Delta p)$ and $Q_{C W}=f(\Delta p)$ experimentally obtained (left) and calculated from equations (39) and (40) (right). 


\section{DISCUSSION}

The research results have proved that for a given pressure drop, in short clearances of the motor working mechanism (i.e. commutation unit clearances), the flow rate of water is at most 3,5 times greater than that of oil (Fig. 13). This ratio decreases with the increasing $\Delta p$ in the motor. Thus, the flow of both water and oil is not a fully developed turbulent flow within, practically, the whole pressure drop range in the motor. For a high pressure drop in the motor (25 MPa), the water/oil flow rate ratio does not exceed 1.5.

The research results have also shown (according to Fig. 19), that:

a) for $\Delta \mathrm{p}=5 \mathrm{MPa} \frac{Q_{C, W}}{Q_{C, O}} \cong 2 ;$;
d) for $\Delta \mathrm{p}=25 \mathrm{MPa} \frac{Q_{C, W}}{Q_{C, O}} \cong 1,4$.

Thus, the use of water instead of oil leads to the increase in volumetric losses in short clearances, for example, by about $40 \%$ at $\Delta \mathrm{p}=25 \mathrm{MPa}$. For comparison, in flat clearances of the motor working mechanism, the flow rate of the $1 \%$ HFA-E emulsion is at least more than ten times greater than the flow rate of oil [28]. It was also observed that with the increasing shaft rotation angle, flow disturbances in both clearances of the commutation unit became smaller. Therefore, the description of the flow rate in short clearances of the commutation unit may base on both formula (22) and formula (24). Formula (22) is more suitable as it can describe the flow in a commutation unit with negative overlap, i.e. for the case $\alpha=0$ when we have $A_{1}>0$ and $A_{2}>0$.

It follows from both formula (22) and formula (24) that the flow rate $\mathrm{Q}_{\mathrm{cm}}$ in short commutation unit clearances depends on the clearance height $\mathrm{h}_{\mathrm{s}}$ and the diameter $\mathrm{D}_{\mathrm{o}}$ of the inflow and outflow hole from the working chambers. It can therefore be assumed that coefficient $\zeta$ is a function of fluid viscosity and geometrical dimensions of the clearance. The value of this coefficient increases with the increasing shaft rotation angle $\alpha$, as the value of the coefficient $K_{1}$ is also increasing (Fig. 18).

For a large rotation angle (here about $\left.1,2^{\circ}\right) \mathrm{Q}_{\mathrm{Cm}}$ nears zero, and then:

$$
\frac{K_{2, O}}{K_{2, W}} \approx \frac{\rho_{W}}{\rho_{O}}=1,14
$$

which is a typical value for the flow in flat clearances of the satellite working mechanism [28].

The experimental research has shown that for both oil and water, the coefficient $\gamma$ is a function of the shaft rotation angle $\alpha$, i.e. the length $\mathrm{L}$ of the clearance (Fig. 12). Furthermore, this coefficient is dependent on the viscosity $\mu$ of the liquid. Hence, $\gamma=f(\mu, L)$. Theoretically, the function describing the relationship between $\gamma, \mu$ and $\mathrm{L}$ should take the asymptotic value of 0.5 and 1 . Such features have modified the function arctan, respectively. Thus, it is proposed as [27]:

$\gamma=0,5 \cdot\left(2,5 \cdot \frac{\mu}{\mu_{R}}\right)^{\frac{\alpha}{4}} \cdot \operatorname{arctg}\left(\left(0,1+\frac{\alpha}{\alpha_{R}}\right)^{\left(\frac{\mu_{R}}{5 \cdot \mu}\right)^{2}}-0,5\right)+0,75$ where:

- $\mu$-dynamic viscosity of the liquid [mPas];

- $\mu_{R}$ - reference dynamic viscosity, here assumed as $\mu_{R}=100$ mPas;

$-\alpha$-shaft rotation angle $\left[^{\circ}\right]$.

The above mathematical formula was determined empirically. The characteristics of coefficient $\gamma$, plotted according to (42) for oil and water, are shown in Fig. 20. These characteristics are somewhat different from the experimental data. Greatest difference occurs for oil and is about $8.5 \%$. As a result, the flow rate $\mathrm{Q}_{\mathrm{Cm}}$, calculated according to (22) (Fig. 20) will also be inaccurate. For oil, within the range of $\alpha=0.2$, this error reaches $38 \%$.
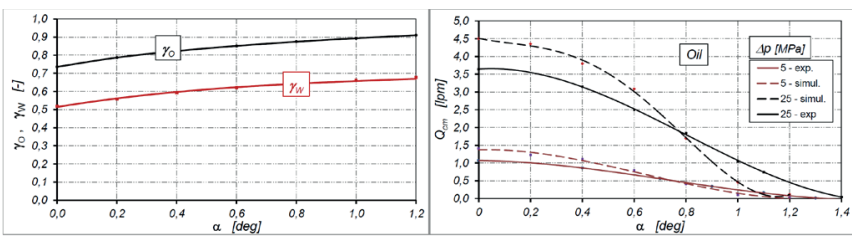

Fig. 20. Characteristics of $\gamma_{O}=f(\alpha)$ and $\gamma_{W}=f(\alpha)$ calculated according to formula (42) for motor supplied with oil and water (left). Characteristics $Q_{C m, O}=f(\alpha)$ calculated according to formula (22) for motor supplied with oil (right).

The values of the average oil flow rate $Q_{C, O}$ and the average water flow rate $\mathrm{Q}_{\mathrm{C}, \mathrm{W}}$ in commutation unit clearances, calculated from the relation (39) and (40) respectively, are higher than those determined experimentally. The smallest differences are observed for the motor supplied with oil and, for example, for $\Delta \mathrm{p}=25 \mathrm{MPa}$ they amount to only $3 \%$, compared to $15 \%$ for water and the same pressure drop.

In the operating mechanism of the motor, the flow rate in commutation unit clearances is one of volumetric loss sources. Other sources include:

- the liquid flow rate in flat clearances of the working mechanism [28];

- the liquid flow rate in the spaces between the teeth of the working mechanism;

- the liquid flow rate caused by cyclic elastic deformation of the working chambers [1];

- the liquid flow rate depending on liquid compressibility [1].

In the overall balance of volumetric losses in the motor supplied with oil, the error of $3 \%$ in the calculation of $\mathrm{Q}_{\mathrm{C}, \mathrm{O}}$ is very small. On the other hand, the error of $15 \%$ in the calculation of $Q_{C, W}$ in the motor supplied with water seems to be large. However, the flow rate $\mathrm{Q}_{C, W}$ in comparison to the flow rate $\mathrm{Q}_{\mathrm{Lfg}, \mathrm{W}}$ of the water in working mechanism flat clearances is at least four times lower. Furthermore, the experiments have shown that the flow rate of the liquid pumped by the spaces between the teeth of the operating mechanism depends on the speed and represents the highest value. Therefore, the $\mathrm{Q}_{\mathrm{C}, \mathrm{W}}$ calculation error at the level of $15 \%$ is acceptable. 


\section{SUMMARY}

The article presents the methodology and experimental results of examination of the flow rate in short clearances in the commutation unit of the working mechanism of a satellite motor. These clearances change their length during motor shaft rotation. The experimental studies have shown that both the oil flow and the water flow in these clearances are turbulent and not fully developed. The mathematical model presented in the article will be used to build a model of volumetric losses in the motor. This model will be the subject of a further publication.

The mathematical model described in the paper will be used to describe the flow rate in satellite pump commutation unit clearances.

The other planned publication will describe the results of CFD calculations of the liquid flow in short clearances of the motor working mechanism. These results will be compared with the results of the experiment and calculations based on the here presented mathematical model.

\section{ACKNOWLEDGMENT}

The article was developed in the framework of the project LIDER/35/102/L-2/10/NCBiR/2011, entitled: New study of hydraulic satellite machines for drives with bioliquids and non-flammable liquids and funded by the National Centre for Research and Development in Poland.

\section{REFERENCES}

1. Balawender A.: Physical and mathematical model of losses in hydraulic motors. Developments in mechanical engineering, Gdansk University of Technology Publishers. Gdansk 2005 .

2. Bing X., Junhui Z., Huayong Y., Bin Z.: Investigation on the Radial Micro-motion about Piston of Axial Piston Pump. Chinese Journal of Mechanical Engineering, Vol. 26, No. 2, 2013. DOI: 10.3901/CJME.2013.02.325.

3. Deptula A., Osinski P., Partyka M..: Identification of influence of part tolerances of 3PWR-SE pump on its total efficiency taking into consideration multi-valued logic trees 60. Polish Maritime Research, 1(93)/2017, vol. 24. DOI: 10.1515/pomr-2017-0006

4. Dymarski C., Dymarski P.: Developing Methodology for Model Tests of Floating Platforms in Low-Depth Towing Tank. Archives of Civil and Mechanical Engineering, No 1/2016, DOI: dx.doi.org/10.1016/j.acme.2015.07.003
5. Gao J., Huang W., Quan L., Huang J.: The distributed parameter model of hydraulic axial piston motor and its application in hydraulic excavator swing systems. Proceedings of the Institution of Mechanical Engineers Part I Journal of Systems and Control Engineering, April 2017. DOI: $10.1177 / 0959651817704098$

6. Gelesz P., Karczewski A., Kozak J., Litwin W., Piatek L.: Design Methodology for Small Passenger Ships on the Example of the Ferryboat Motława 2 Driven by Hybrid Propulsion System. Polish Maritime Research, special issue S1 (93) 2017, vol. 24. DOI: 10.1515/pomr-2017-0023

7. Guzowski A., Sobczyk A.: Reconstruction of hydrostatic drive and control system dedicated for small mobile platform. American Society of Mechanical Engineers, 2014. DOI: dx.doi.org/10.1115/FPNI2014-7862.

8. Jasinski R.: Problems of the starting and operating of hydraulic components and systems in low ambient temperature (Part I). Polish Maritime Research, No 4/2008. DOI: 10.2478/v10012-007-0095-9.

9. Jasinski R.: Problems of the starting and operating of hydraulic components and systems in low ambient temperature (Part II). Polish Maritime Research, No 1/2009. DOI: $10.2478 / \mathrm{v10012-008-0012-x.}$

10. Jasinski R.: Problems of the starting and operating of hydraulic components and systems in low ambient temperature (Part III). Methods of determining parameters for correct start-ups of hydraulic components and systems in low ambient temperatures. Polish Maritime Research, No 4/2009. DOI: 10.2478/v10012-008-0052-2.

11. Ke M., Ding F., Li B., Chen Z.: Exploration of the influence of backing pressure on the efficiency of hydraulic motor. Nongye Jixie Xuebao/Transactions of the Chinese Society of Agricultural Machinery, 37(10), October 2006.

12. Kollek W., Osinski P., Wawrzynska U.: The influence of gear micropump body asymmetry on stress distribution. Polish Maritime Research, 2(65)/2010. DOI: 10.1515/ pomr-2017-0007.

13. Landvogt B., Osiecki L., Patrosz P., Zawistowski T., Zylinski B.: Numerical simulation of fluid-structure interaction in the design process for a new axial hydraulic pump. Progress in Computational Fluid Dynamics, Vol. 14, Issue 1, 2014. DOI:doi.org/10.1504/PCFD.2014.059198.

14. Litwin W., Olszewski A.: Water-Lubricated Sintered Bronze. Journal Bearings - Theoretical and Experimental Research. Tribology Transactions, vol. 57, No 1/2014. 
15. Lubinski J., Sliwinski P. Multi parameter sliding test result evaluation for the selection of material pair for wear resistant components of a hydraulic motor dedicated for use with environmentally friendly working fluids. Solid State Phenomena Vol. 225(2015). DOI: 10.4028/www.scientific. net/SSP.225.115.

16. Maczyszyn A.: Evaluation of losses in a hydraulic motor based on the SWSB - 63 motor tests. Polish Maritime Research, 4(17)/2010. DOI: 10.2478/v10012-010-0035-y.

17. Maczyszyn A.: Method of Sum of Power Losses as a Way for Determining the ki Coefficients of Energy Losses in Hydraulic Motor. Polish Maritime Research, 2(23)/2016. DOI: 10.1515/pomr-2016-0021.

18. Osiecki L., Patrosz P., Landvogt B., Piechna J., Zawistowski T., Zylinski B.: Simulation of fluid structure interaction in a novel design of high pressure axial piston hydraulic pump. Archive of Mechanical Engineering. The Journal of Committee on Machine Building of Polish Academy of Sciences, Vol. 60, Issue 4, 2013. DOI: 10.2478/ meceng-2013-0031.

19. Osiecki L., Patrosz P., Zawistowski T., Landvogt B., Piechna J., Zylinski B.: Compensation of pressure peaks in PWK type hydraulic pumps. Key engineering materials, Vol. 490, 2011. DOI: 10.4028/www.scientific.net/KEM.490.33.

20. Osinski P., Deptula A., Partyka M.: Discrete optimization of a gear pump after tooth root undercutting by means of multi-valued logic trees. Archives of Civil and Mechanical Engineering, No 4/2013, DOI: 10.1016/j.acme.2013.05.001.

21. Paszota Z.: Energy losses in hydrostatic drive. LAP LAMBERT Academic Publishing, 2016.

22. Paszota Z.: Energy losses in the hydraulic rotational motor - definitions and relations for evaluation of the efficiency of motor and hydrostatic drive. Polish Maritime Research, 2(65)/2010. DOI: 10.2478/v10012-010-0017-0.

23. Paszota Z.: Power of energy losses in hydrostatic drive system elements - definition, relationships, ranges of changes, energy efficiencies. Part 1 - hydraulic motor. Drives and Control, 11/2007, Poland.

24. Patrosz P.: Deformation in the axial clearance compensation node in the satellite pump unit. Hydraulics and Pneumatics $1 / 2014$, Poland.

25. Pobedza J., Sobczyk A.: Properties of high pressure water hydraulic components with modern coatings. Advanced Materials Research. Trans Tech Publications Ltd, 849/2014. DOI: 10.4028/www.scientific.net/AMR.849.100.
26. Sliwinski P.: New satellite pumps. Key Engineering Materials, No 490/2012. DOI: 10.4028/www.scientific. net/KEM.490.195.

27. Sliwinski P.: The basics of design and experimental tests of the commutation unit of a hydraulic satellite motor. Archives of Civil and Mechanical Engineering, No 16/2016, DOI: 10.1016/j.acme.2016.04.003.

28. Sliwinski P.: The flow of liquid in flat gaps of satellite motors working mechanism. Polish Maritime Research 2/2014. DOI: 10.2478/pomr-2014-0019.

29. Sliwinski P.: The influence of water and mineral oil on volumetric losses in a hydraulic motor. Polish Maritime Research, special issue S1 (93) 2017, vol. 24. DOI: 10.1515/ pomr-2017-0041.

30. Walczak P., Sobczyk A.: Simulation of water hydraulic control system of Francis turbine. American Society of Mechanical Engineers, 2014. doi: dx.doi.org/10.1115/ FPNI2014-7814.

31. Wu D., Burton R., Schoenau G., Bitner D.: Modeling of orifice flow rate at very small openings. International Journal of Fluid Power, vol. 4, No. 1, April 2003.

32. Wu D., Burton R., Schoenau G.: An empirical discharge coefficient model for orifice flow. International Journal of Fluid Power, vol. 3, No. 3, December 2002.

33. Xiaogang Z., Long Q., Yang Y., Chengbin W., Liwei Y.: Output Characteristics of a Series Three-port Axial Piston Pump. Chinese Journal of Mechanical Engineering, Vol. 25, No. 3, 2012. DOI: 10.3901/CJME.2012.03.498.

34. Yu H., Luo C., Wang H.: Performances of a Balanced Hydraulic Motor with Planetary Gear Train. Chinese Journal of Mechanical Engineering, Vol. 25, No. 4, 2012. DOI: 10.3901/CJME.2012.04.760.

35. Zloto T., Nagorka A.: An efficient FEM for pressure analysis of oil film in a piston pump. Applied Mathematics and Mechanics, vol. 30, No 1/2009.

\section{CONTACT WITH THE AUTHOR}

\author{
Paweł Śliwiński \\ e-mail:pawel.sliwinski@pg.gda.pl \\ Gdansk University of Technology \\ Narutowicza 11/12 \\ 80-233 Gdansk \\ Poland
}

